\title{
Enhanced Vapor Transmission Barrier Properties via Silicon-Incorporated Diamond-Like Carbon Coating
}

\author{
Parand R. Riley ${ }^{1}$, Pratik Joshi ${ }^{1}{ }^{1}$, Sina Azizi Machekposhti ${ }^{2}$, Ritesh Sachan ${ }^{3}$, Jagdish Narayan ${ }^{1}$ \\ and Roger J. Narayan ${ }^{2, *(D)}$ \\ 1 Department of Materials Science and Engineering, Centennial Campus, North Carolina State University, \\ Raleigh, NC 27695-7907, USA; prostam@ncsu.edu (P.R.R.); pjoshi5@ncsu.edu (P.J.); narayan@ncsu.edu (J.N.) \\ 2 Joint Department of Biomedical Engineering, Centennial Campus, North Carolina State University, \\ Raleigh, NC 27695-7115, USA; sazizim@ncsu.edu \\ 3 Department of Mechanical Engineering, Oklahoma State University, Stillwater, OK 74078, USA; \\ rsachan@okstate.edu \\ * Correspondence: rjnaraya@ncsu.edu
}

Citation: Riley, P.R.; Joshi, P.; Azizi Machekposhti, S.; Sachan, R.;

Narayan, J.; Narayan, R.J. Enhanced Vapor Transmission Barrier Properties via Silicon-Incorporated Diamond-Like Carbon Coating. Polymers 2021, 13, 3543. https:// doi.org/10.3390/polym13203543

Academic Editor: Giulio Malucelli

Received: 10 September 2021

Accepted: 11 October 2021

Published: 14 October 2021

Publisher's Note: MDPI stays neutral with regard to jurisdictional claims in published maps and institutional affiliations.

Copyright: (c) 2021 by the authors. Licensee MDPI, Basel, Switzerland. This article is an open access article distributed under the terms and conditions of the Creative Commons Attribution (CC BY) license (https:// creativecommons.org/licenses/by/ $4.0 /)$.

\begin{abstract}
In this study, we describe reducing the moisture vapor transmission through a commercial polymer bag material using a silicon-incorporated diamond-like carbon (Si-DLC) coating that was deposited using plasma-enhanced chemical vapor deposition. The structure of the Si-DLC coating was analyzed using scanning electron microscopy, Raman spectroscopy, X-ray photoelectron spectroscopy, energy-dispersive X-ray spectroscopy, selective area electron diffraction, and electron energy loss spectroscopy. Moisture vapor transmission rate (MVTR) testing was used to understand the moisture transmission barrier properties of Si-DLC-coated polymer bag material; the MVTR values decreased from $10.10 \mathrm{~g} / \mathrm{m}^{2} 24 \mathrm{~h}$ for the as-received polymer bag material to $6.31 \mathrm{~g} / \mathrm{m}^{2} 24 \mathrm{~h}$ for the Si-DLC-coated polymer bag material. Water stability tests were conducted to understand the resistance of the Si-DLC coatings toward moisture; the results confirmed the stability of Si-DLC coatings in contact with water up to $100{ }^{\circ} \mathrm{C}$ for $4 \mathrm{~h}$. A peel-off adhesion test using scotch tape indicated that the good adhesion of the Si-DLC film to the substrate was preserved in contact with water up to $100^{\circ} \mathrm{C}$ for $4 \mathrm{~h}$.
\end{abstract}

Keywords: coating; surface structure; moisture vapor transmission; silicon-incorporated diamondlike carbon; plasma-enhanced chemical vapor deposition; water stability

\section{Introduction}

Diamond-like carbon (DLC) is an amorphous variety of carbon made up of trigonally and tetrahedrally hybridized carbon atoms; nanoscale or microcrystalline graphitic regions are commonly noted within the amorphous matrix [1]. In 1971, Aisenberg et al. grew amorphous and insulating carbon coatings using a beam of carbon ions that was created in an argon plasma; the term "diamond-like" was used to indicate that the properties of this coating are similar to those of diamond [2]. The deposition of DLC coatings requires an energy source that is used to generate excited carbon species from laser-carbon target interaction, arc discharge, acceleration of carbon ions, or interaction with energetic ions (e.g., sputtering).

DLC has several positive attributes as a barrier coating: (a) it exhibits a high atomic density, (b) it can be deposited on a temperature-sensitive (e.g., polymer) surface, (c) it can be deposited at low cost using cost-effective precursor materials [3-5], and (d) DLC is a promising material that is being considered for biocompatible barrier applications alongside carbon nanostructures such as graphene and fullerenes [6]. Several studies have considered the use of DLC as a barrier coating [3-5]. In 2004, Abbas et al. described the use of hydrogenated DLC coatings deposited by radio frequency plasma-enhanced chemical vapor deposition to improve the gas barrier properties of polycarbonate and polyethylene 
terephthalate [4]. The lower density hydrogenated DLC coating was shown to impart better gas barrier activity, as evidenced by a lower water vapor transmission rate, than the higher density hydrogen-free DLC coating.

In another study, Boutroy et al. examined the gas barrier properties of hydrogenated DLC coatings that were grown on polyethylene terephthalate substrates using a microwave plasma-enhanced chemical vapor deposition process that was optimized for coating bottles in a short amount of time [5]. Using a Mocon gas permeation instrument, they showed that a $40 \mathrm{~nm}$ thick hydrogenated DLC coating significantly reduced oxygen transmission. They demonstrated that an increase in shelf life of beer and soft drinks could be obtained through the use of the hydrogenated DLC coating. Casiraghi et al. subsequently showed that microwave plasma-enhanced chemical vapor deposition is able to (a) coat bottles at a relatively high rate of $60 \mathrm{~nm} / \mathrm{s}$ and (b) uniformly coat bottles, with only a $15 \%$ variation in thickness over the length of the bottle [3]. Zhang et al. coated polyethylene terephthalate with hydrogenated DLC using radio frequency plasma-enhanced chemical vapor deposition [3]; they used a radio frequency (RF) power of $600 \mathrm{~W}$, an argon:acetylene ratio of 1:2, and a gas flow rate of 40 SCCM to create hydrogenated DLC coatings and demonstrated the barrier properties of the hydrogenated DLC coatings.

Silicon-incorporated DLC coatings represent another potentially suitable material for use in barrier applications. In a recent study, the structure and cell viability properties of Si-DLC coatings on fused silica substrates were demonstrated [7]. X-ray photoelectron spectroscopy (XPS) indicated that the coatings contained carbon, oxygen, and silicon; $\mathrm{sp}^{2}$ $(\mathrm{C}=\mathrm{C}), \mathrm{sp}^{3}(\mathrm{C}-\mathrm{C}), \mathrm{C}-\mathrm{O}$, and $\mathrm{C}=\mathrm{O}$ bonds were noted in the coatings. Fourier transform infrared spectroscopy (FTIR) analysis showed the presence of spectral features associated with C-OH stretching, $\mathrm{Si}-\mathrm{CH}_{2}$ bending, and C-H bending. $\mathrm{L} 929$ fibroblast-like cells showed no statistically significant difference in cell viability when cultured on Si-DLC coatings or uncoated fused silica [7].

The water barrier properties of DLC coatings have previously been demonstrated. For example, additively manufactured polymers suffer from high water permeation rates, which limit their functionality and shelf life. Dangnan et al. reported a water vapor transmission rate (WVTR) reduction of up to $70 \%$ by applying nitrogen-modified DLC coatings to additively manufactured polymers [8]. The reduction in the water permeation rate was associated with the diffusion barrier properties of the amorphous hydrogenated carbon (a-C:H) coatings [9]. Abbas et al. investigated the water vapor permeation of silicon-doped hydrogenated amorphous carbon (Si-a:C:H) coatings. The Si-a:C:H coatings exhibited a significantly lower WVTR value $\left(0.03 \mathrm{~g} / \mathrm{m}^{2} 24 \mathrm{~h}\right)$ in comparison with the undoped DLC coatings $\left(1.3 \mathrm{~g} / \mathrm{m}^{2} 24 \mathrm{~h}\right)$. This result was attributed to the internal stress reduction in the DLC coating that was associated with the incorporation of silicon [10].

In the present work, silicon-incorporated diamond-like carbon (Si-DLC) coatings were deposited on a commercial polymer material in the shape of a cylindrical bag using plasma-enhanced chemical vapor deposition (PECVD) with a silicon-containing precursor. In addition to materials characterization of the Si-DLC coating, the moisture vapor transmission rate of Si-DLC coated polymer material was compared with that of the uncoated material. These results showed the effectiveness of the Si-DLC coating for reducing the moisture vapor transmission rate of the commercial polymer from $10.10 \mathrm{~g} / \mathrm{m}^{2} 24 \mathrm{~h}$ to $6.31 \mathrm{~g} / \mathrm{m}^{2} 24 \mathrm{~h}$. The successful reduction in the MVTR value was associated with stress reduction in the DLC coatings; enhanced adhesion and decreased crack formation in the coating was associated with the incorporation of silicon. The use of the PECVD process with silicon-containing precursors is an effective approach to cover large area surfaces with adherent Si-DLC coatings.

\section{Materials and Methods}

The commercial polymer material in a cylindrical shape with a diameter of $20.3 \mathrm{~cm}$ and a height of $17.8 \mathrm{~cm}$ (ILC Dover, Federica, DE, USA) and Si (100) substrates were cleaned via ultrasonication in an acetone bath for 5 minutes and then in a methanol bath for 
$5 \mathrm{~min}$; the substrates were immediately transferred to the chamber of the PECVD system for deposition of the Si-DLC coating. A RF plasma-enhanced chemical vapor deposition (PECVD) system was used to deposit Si-DLC coatings on the substrates. The PECVD instrument is an in-house assembled system that is designed for plasma generation in the capacitively coupled mode. The system contains a stainless-steel cylindrical chamber that is customized for the deposition of coatings on large substrates. In the capacitively coupled mode, the driving electrode with a diameter of 12 inches performs as the substrate holder and is located on the bottom plate of the chamber. The electrode is attached to an RFX-600 power supply with a $13.56 \mathrm{MHz}$ frequency, which is electrically insulated from the remainder of the chamber and serves as the counter electrode; the counter electrode is grounded. The chamber is equipped with a water-coolingsystem. The pumping system provides a base pressure of approximately $2 \times 10^{-8}$ Torr. The process gases flowed inside the chamber from above and through a showerhead distribution ring (Figure 1). The substrates were loaded on the chamber base and were in direct contact with the planar electrode. The deposition process was comprised of loading, plasma cleaning, plasma deposition, and unloading steps. After a pump-down for at least three hours that allowed a base pressure of $10^{-8}$ Torr to be attained, a plasma cleaning step was performed for $10 \mathrm{~min}$ using argon and oxygen gases with a mass flow rate of 90 SCCM and 50 SCCM, respectively. During the cleaning step, the peak-to-peak voltage $\left(\mathrm{V}_{\mathrm{pp}}\right)$ was kept at $400 \pm 10 \mathrm{~V}$, which led to an RF power of $81 \pm 10 \mathrm{~W}$ and a DC bias of $-140 \pm 10 \mathrm{~V}$. The Si-DLC coating was deposited using 1.6 SCCM of tetramethylsilane (TMS) and 90 SCCM of argon. The deposition step was performed for 60 minutes with a $V_{p p}$ of $300 \pm 10 \mathrm{~V}$, leading to an RF power of $117 \pm 10 \mathrm{~W}$ and a DC bias of $149 \pm 10 \mathrm{~V}$. During cleaning and deposition steps, the total pressure was maintained at 50 mTorr as measured by a Baratron gauge (MKS Instruments, Andover, MA, USA).

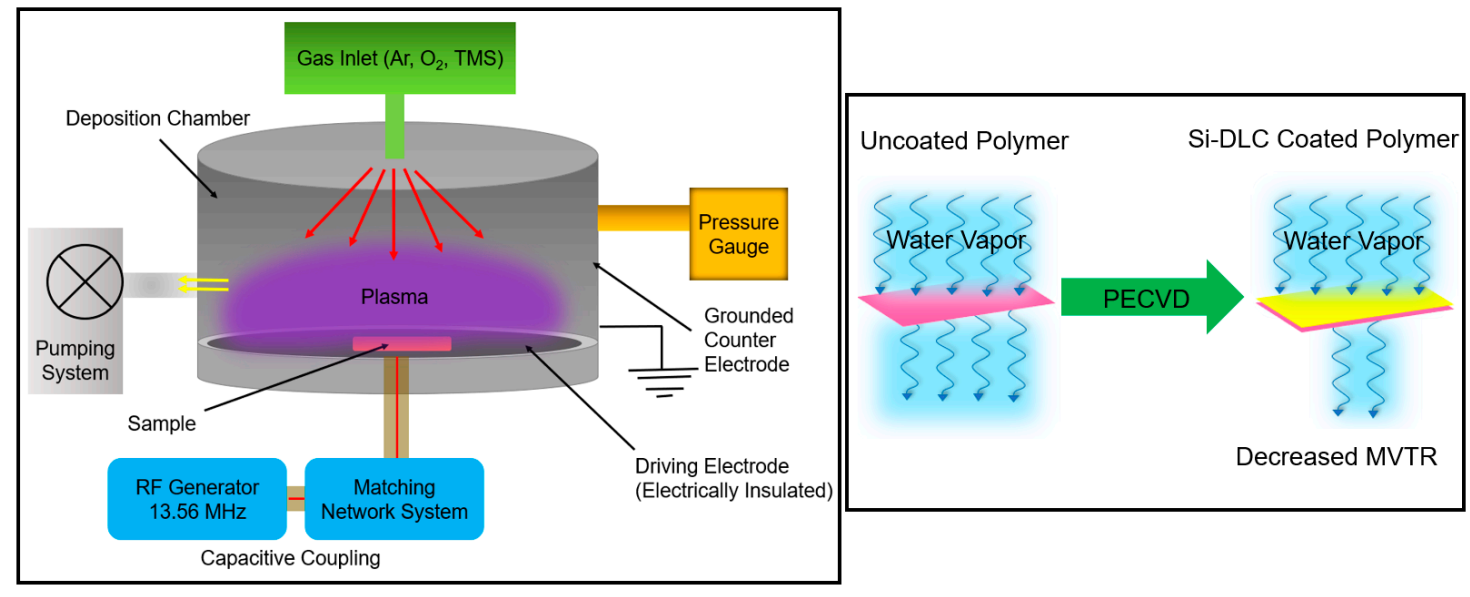

Figure 1. Schematic of the PECVD system used for the deposition of the Si-DLC coatings (left box); the use of the Si-DLC coating to decrease the moisture vapor transmission rate (right box).

The thickness of the Si-DLC coatings was evaluated using the conventional step height approach with a Dektak D150 contact profilometer (Veeco, Plainview, NY, USA) with a tip size radius of $12.5 \mu \mathrm{m}$. The thickness of five different points of the coating was measured and averaged. Since the thickness measurements of Si-DLC coating on the polymer material were difficult to perform and the results were inconclusive, thickness measurements were performed on identical Si-DLC coatings that were grown on silicon (100) substrates. The morphology and roughness of the Si-DLC coatings on polymer material and silicon substrates were examined using an MFP-3D Origin + atomic force microscope (AFM) (Asylum Research, Goleta, CA, USA) in tapping mode with a resonant frequency of approximately $50 \mathrm{kHz}$, a scan size of $2 \mu \mathrm{m} \times 2 \mu \mathrm{m}$, and a scan rate of 0.75 lines per second. A Verios 460L field emission scanning electron microscope (FESEM) (FEI, Waltham, MA, USA) with a resolution of $0.6 \mathrm{~nm}$ was used to understand the surface 
morphology of the Si-DLC coatings on the polymer material and silicon substrates. The bonding characteristics of the DLC coating on the silicon substrate were investigated using an alpha300 M Raman microscope (WITec, Ulm, Germany). The Raman system was operated with a solid-state green light laser $(=532 \mathrm{~nm})$, a spot size of $\sim 2 \mu \mathrm{m}$ diameter, and a UHTS 300 spectrometer (WITec, Ulm, Germany). The Raman instrument was calibrated with the $520.6 \mathrm{~cm}^{-1}$ peak that is associated with the silicon wafer. X-ray photoelectron spectroscopy (XPS) was performed to understand the carbon bonding hybridization and the elemental composition of the Si-DLC coating on a silicon substrate. X-ray photoelectron spectroscopy was performed using a FlexMod spectrometer (SPECS Surface Nano Analysis $\mathrm{GmbH}$, Berlin, Germany) with an $\mathrm{Mg} \mathrm{K} \alpha(1254 \mathrm{eV})$ excitation source and a PHOIBIS 150 hemispherical analyzer. The energy calibration involved referencing to adventitious carbon, the C 1s line located at $285.0 \mathrm{eV}$. High-resolution transmission electron microscopy (HRTEM) imaging, electron diffraction, energy dispersive X-ray (EDS), and electron energyloss spectroscopy (EELS) were performed using a Talos-F200 microscope (FEI, Waltham, MA, USA) with an 'XFEG' Schottky field emission gun source at $200 \mathrm{keV}$. EELS scans were also performed with Talos using an electron current of $35 \mathrm{pA}$ and a collection angle of $25 \mathrm{mrad}$; high-resolution scans were performed at $0.1 \mathrm{eV} /$ channel. The moisture vapor transmission rate (MVTR) test was performed on Si-DLC coated and uncoated polymer materials to understand the functionality of Si-DLC coating for vapor transmission barrier applications. All of the samples were cut into 3.5-inch diameter circular swatches. Three uncoated polymer materials and three Si-DLC coated polymer materials were tested under standard atmosphere laboratory conditions of $21 \pm 2{ }^{\circ} \mathrm{C}$ with $65 \pm 5 \%$ relative humidity $(\mathrm{RH})$. The moisture vapor diffusion rate through the Si-DLC coated and uncoated polymer materials was determined according to the Simple Dish Method, which is similar to ASTM E96-80. The samples are placed on water dishes with a diameter of $82 \mathrm{~mm}$ and a depth of $19 \mathrm{~mm}$; a $9 \mathrm{~mm}$ air space was maintained between the polymer materials and the water surface. A vibration-free turntable containing eight dishes was rotated uniformly at a rate of 2 meters per minute; this approach ensured that all of the dishes were subjected to identical average ambient conditions during testing. The assembled specimen dishes were permitted to stabilize for $2 \mathrm{~h}$ prior to measurement of the initial weight. The assembled specimen dishes were weighed again after a 24-hour interval. The moisture vapor loss rate (MVTR) was calculated from these measurements in units of $\mathrm{g} / \mathrm{m}^{2}-24 \mathrm{~h}$. For the water stability experiments, Si-DLC coatings on silicon substrates were immersed in a deionized (DI) water bath for four hours. For one set of the samples, the water temperature was kept at room temperature; for the other set of the samples, the water bath was maintained at $100{ }^{\circ} \mathrm{C}$ using a hot plate.

\section{Results and Discussions}

The PECVD process provides several advantages over other CVD processes. The plasma component in the PECVD process facilitates the decomposition of the gaseous precursors and reduces the substrate temperature that is required for the coating process [11,12]. Hence, the PECVD process is compatible with the growth of coatings on polymer and other heat-sensitive substrates. In addition, the PECVD process enables the deposition of coatings with controlled compositions and provides straightforward control over the reaction parameters [11-13]. PECVD allows for the conformal deposition and step coverage of substrates; a uniformly-shaped plasma may allow for the deposition of coatings over large areas $[12,14]$. Plasma pretreatment may be performed prior to deposition of the PECVD coating; plasma pretreatment increases the surface energy of the substrate by eliminating organic contaminants. The adhesion of the coating to the substrate may be enhanced by plasma pretreatment [15]. During the PECVD deposition process, the bombardment of the substrate with energetic particles increases the adhesion of coating through energetic particle implantation and enhanced surface mobility [16]. In addition, the PECVD process allows for precise control over the coating thickness [17]. As such, PECVD is an appropriate approach for the deposition of Si-DLC coatings over a large area on heat-sensitive polymer 
substrates. It should be noted that the PECVD process has several limitations. It requires complicated and expensive equipment. During the PECVD process, the buildup of toxic and explosive gaseous byproducts must be controlled. The PECVD process also suffers from the slower rate of growth than other methods such as pulsed laser annealing $[18,19]$.

The thickness of the Si-DLC coatings on Si substrates was measured at five random positions on the coating; the measured thickness value was $380 \pm 19 \mathrm{~nm}$. This thickness value corresponds to a deposition rate of $\sim 6 \mathrm{~nm} /$ minute. Figure 2 contains the $2 \mathrm{D}$ and $3 \mathrm{D}$ AFM results from Si-DLC coatings on the polymer material (Figure $2 a, b$ ) and Si substrate (Figure 2c,d). No pinholes were noted on the coated surfaces. The root-mean-square (RMS) roughness values over a $2 \mu \mathrm{m} \times 2 \mu \mathrm{m}$ surface area of the Si-DLC coating on the polymer material and the Si-DLC coating on the Si substrate were $86.5 \pm 45 \mathrm{~nm}$ and $0.58 \pm 0.3 \mathrm{~nm}$, respectively. The RMS values of the uncoated polymer substrate and silicon substrate were $10.658 \pm 8 \mathrm{~nm}$ and $0.7+/-0.2 \mathrm{~nm}$, respectively. The low RMS roughness values of the Si-DLC coating on both substrates indicated the uniformity of the coating.
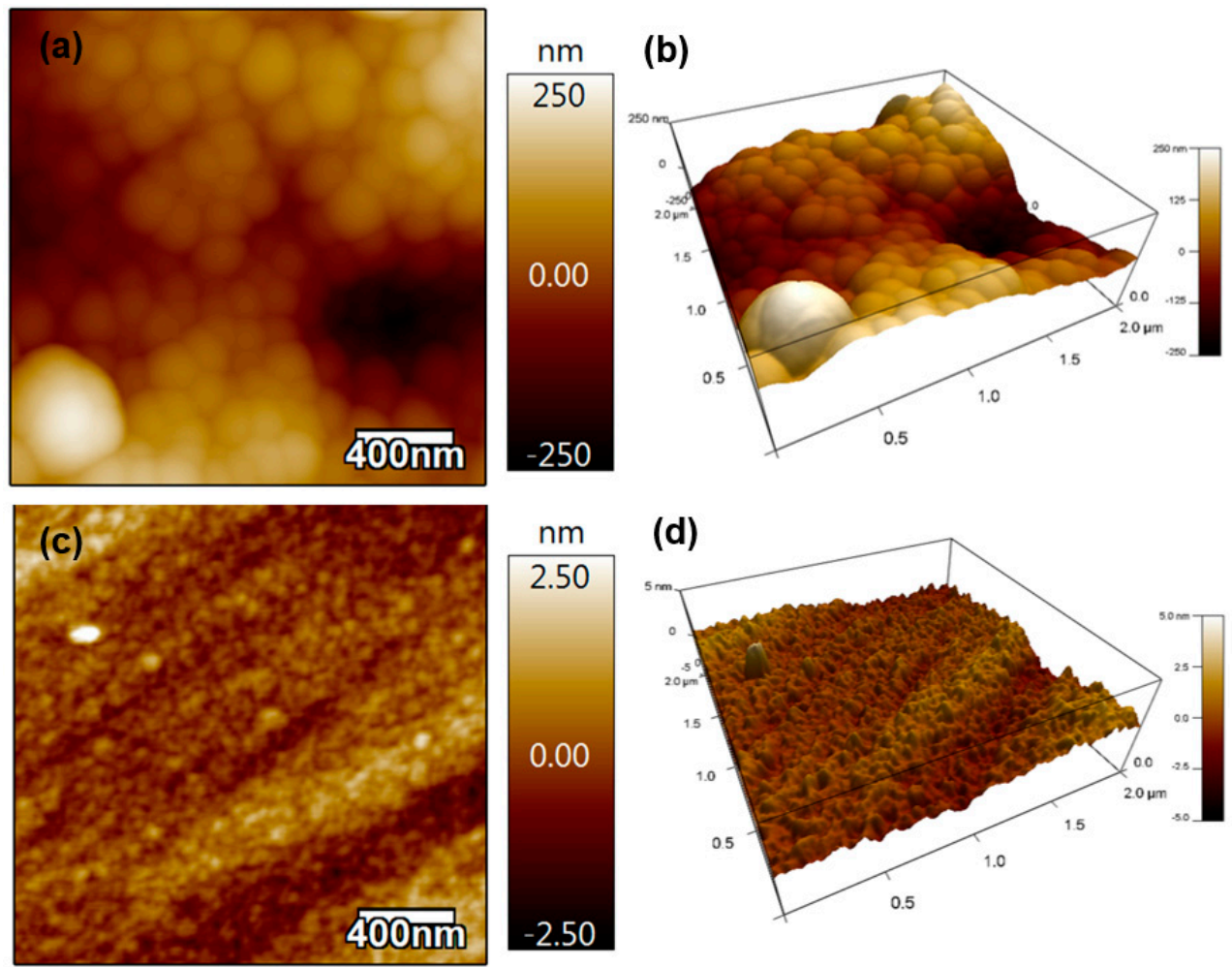

Figure 2. (a) The 2D AFM image of the Si-DLC coating on the polymer material, (b) the 3D AFM image of Si-DLC coating on the polymer material, (c) the 2D AFM image of Si-DLC coating on the Si substrate, and (d) the 3D AFM image of Si-DLC coating on the Si substrate.

Figure $3 \mathrm{a}, \mathrm{b}$ contain FESEM images of the uncoated polymer material; Figure $3 \mathrm{c}, \mathrm{d}$ contain FESEM images of the Si-DLC coated polymer material. The granular features exhibit an average size of $200 \mathrm{~nm}$; the images also indicate the uniformity of the Si-DLC coating. No flaking of the coating or uncoated areas was observed over an area of $\sim 15 \mu \mathrm{m}^{2}$ in Figure 3c. These results are consistent with previous micro-scratch testing of the SiDLC coating on fused silica, which revealed a high critical load for $2.961 \pm 0.292 \mathrm{~N}$ and chipping as the only mode of failure [7]. The presence of Si in the Si-DLC coating may serve to enhance the adhesion of the Si-DLC coating to the substrate [20,21]; for example, the presence of Si may also enhance film adhesion through the reduction in stress in the Si-DLC coating [22]. 

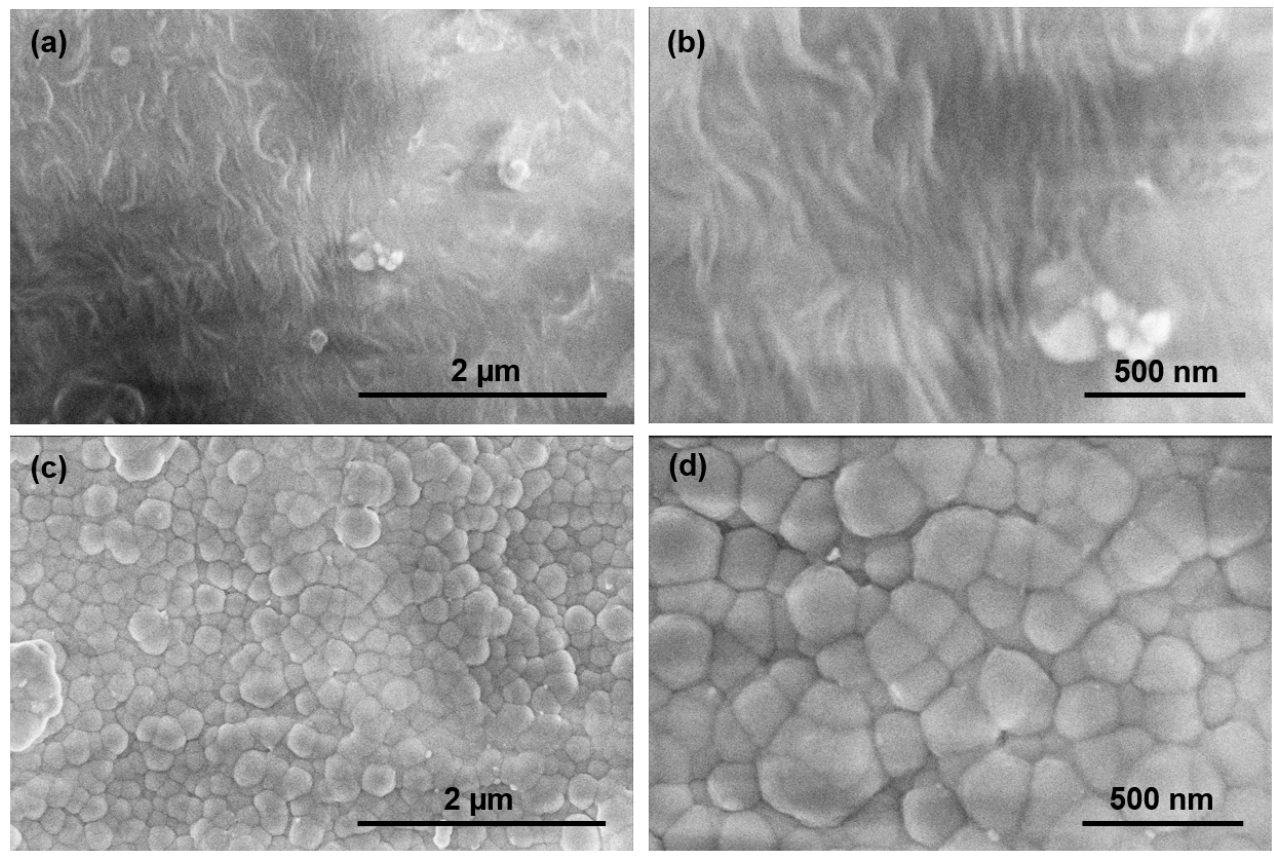

Figure 3. (a,b) FESEM images of the uncoated polymer material. (c,d) FESEM images of the Si-DLC coated polymer material.

Raman spectroscopy is a powerful tool to understand carbon bonding in carboncontaining coating. Figure 4 contains the Raman spectrum obtained from the Si-DLC coating on the silicon substrate over the range of 800 to $2000 \mathrm{~cm}^{-1}$. Since distinguishing between the Raman spectral features associated with carbon bonding in the polymer material and the Si-DLC coating is difficult, we acquired the Raman spectrum from a Si-DLC coating on a silicon substrate. The peak around $1000 \mathrm{~cm}^{-1}$ is attributed to the silicon substate. In DLC coatings, the Raman spectrum takes the shape of a broad band between $1100 \mathrm{~cm}^{-1}$ and $1700 \mathrm{~cm}^{-1}$, which is comprised of two peaks at approximately $1350 \mathrm{~cm}^{-1}$ and $1580 \mathrm{~cm}^{-1}$. The $\mathrm{D}$ peak at $\sim 1350 \mathrm{~cm}^{-1}$ is assigned to the $A_{1 \mathrm{~g}}$ symmetric breathing mode; the $G$ peak at $\sim 1580 \mathrm{~cm}^{-1}$ is assigned to the zone-center mode of $\mathrm{E}_{2 \mathrm{~g}}$ symmetry [23-25]. The visible wavelength excitation source used in this study preferentially resonates with $\pi$ states. Therefore, the $\mathrm{sp}^{2}$ bonds ( $\pi$ bonding) are detected 50 to 230 times more strongly than the $\mathrm{sp}^{3}$ bonds ( $\sigma$ bonding); the $\mathrm{D}$ peak appears as a shoulder peak $[7,23,25]$. In Figure 4, a Gaussian distribution was utilized for the deconvolution of the $D$ and $G$ peaks from the broad DLC band; the D and G fit-peaks are located at $1349 \mathrm{~cm}^{-1}$ and $1482 \mathrm{~cm}^{-1}$, respectively. In comparison with DLC coatings, Si-DLC structures show a downshift in the positions of the D and G peaks [26]. There are several reasons for the downshift of the D and G peaks with the incorporation of silicon in the DLC coating. In contrast with carbon atoms that form three-fold- and four-fold-coordinated bonds, silicon atoms form four-fold-coordinated bonding in DLC structures. Since silicon cannot form $\pi$-bonds when present in DLC structures, the $\mathrm{sp}^{3}$ to $\mathrm{sp}^{2}$ ratio in Si-DLC coatings increases, and the size of the graphite-like domains is reduced. The enhancement in $\mathrm{sp}^{3}$ content with the addition of silicon also reduces the internal residual stress in the DLC coatings. Consequently, silicon incorporation increases the adhesion of the Si-DLC coating to the substrate [15]. Therefore, the downshift in the position of D and G peaks in Si-DLC films is partially attributed to the reduction in the internal compressive stress that is associated with the presence of the silicon atoms. In other words, the vibration of the de-strained bonds occurs at lower frequencies. Moreover, the addition of silicon to the DLC coatings weakens the carbon-carbon bonds through the formation of silicon-carbon bonds, which culminates in a downshift in the frequency of $D$ and $G$ peaks and a reduction in the $I_{D} / I_{G}$ ratio [27]. 


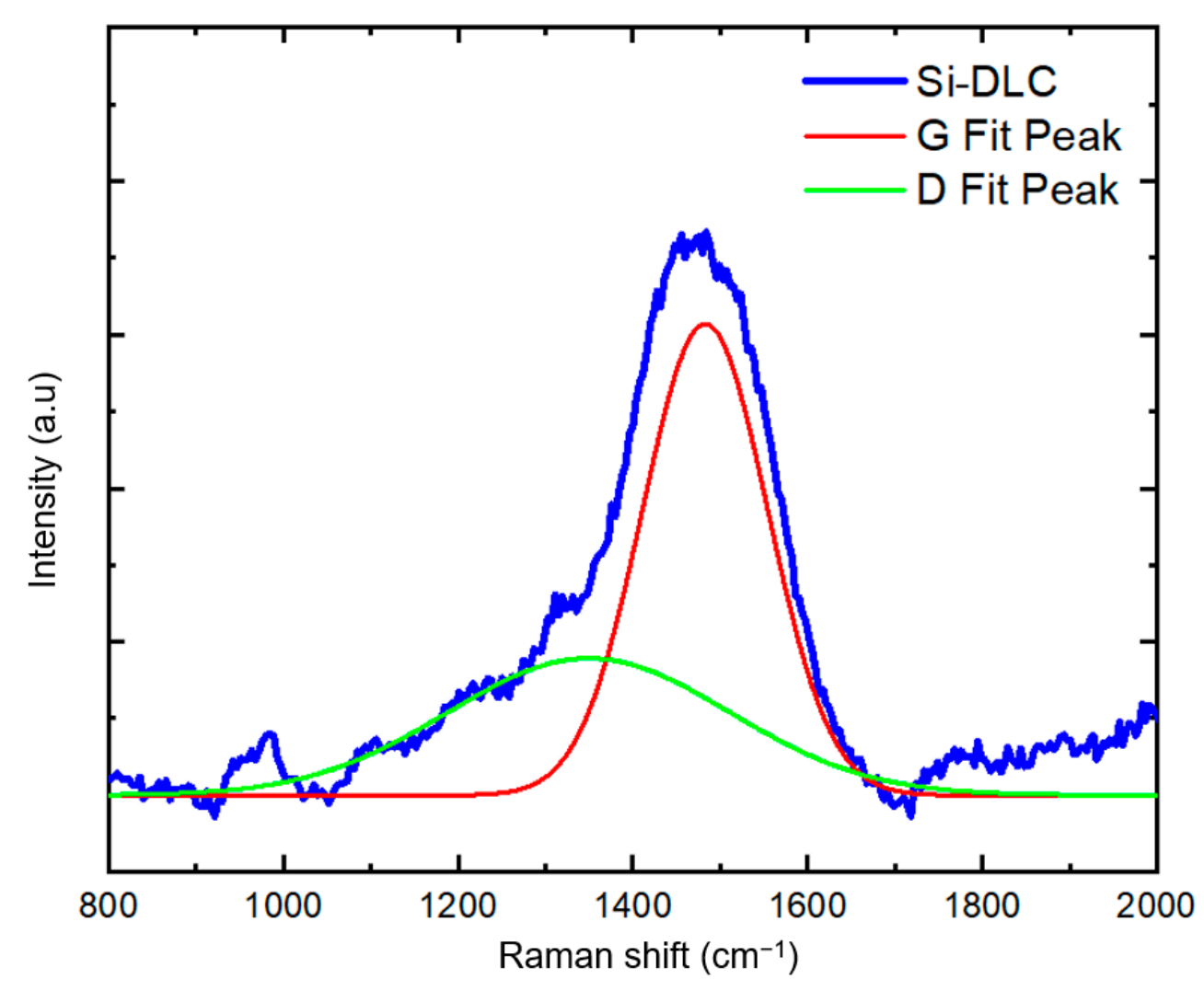

Figure 4. Raman spectrum obtained from the Si-DLC coating on a silicon substrate.

X-ray photoelectron spectroscopy (XPS) was used to obtain information on the elemental composition and the carbon bonding on the surface of the Si-DLC coating. Figure 5a shows the spectrum from the Si-DLC coating and Figure $5 b$ shows the deconvolution of the high-resolution $C 1$ s band. The Shirley model was used for the background determination [28]. The atomic percentages are presented in Table 1. The results indicate the absence of impurities on the surface and provide the elemental compositions for carbon, silicon, and oxygen. The deconvolution of the $C 1$ s peak (Figure $5 b$ ) was used to obtain bonding information for the Si-DLC coating. The $\mathrm{sp}^{2}$-hybridized carbon bonds $(284.2 \mathrm{eV})$, $\mathrm{sp}^{3}$-hybridized Si-C bonds (283.5 eV), sp ${ }^{3}$-hybridized carbon bonds (C-C at $285 \mathrm{eV}$ ), C-O bonds $(286.6 \mathrm{eV}), \mathrm{C}=\mathrm{O}$ bonds $(287.9 \mathrm{eV})$, and $\mathrm{O}-\mathrm{C}=\mathrm{O}$ bonds $(289.3 \mathrm{eV})$ were noted to be present on the surface of Si-DLC coatings; previous studies have also described the presence of these bonds in Si-DLC coating [29-31].

Table 1. The XPS curve fitting results from C 1s, Si 2p, and O 1s peaks corresponding with Figure $5 \mathrm{a}$.

\begin{tabular}{ccccc}
\hline \multirow{2}{*}{ Coated Layer } & \multirow{2}{*}{ Parameter } & \multicolumn{3}{c}{ Peaks in XPS Spectrum } \\
\cline { 3 - 5 } & & C 1s & Si 2p & O 1s \\
\hline \multirow{3}{*}{ Si-DLC } & Position (eV) & 285.3 & 101.8 & 532.8 \\
& FWHM (eV) & 2.14 & 2.87 & 2.01 \\
& Atomic \% & 59.1 & 16 & 24.9 \\
\hline
\end{tabular}



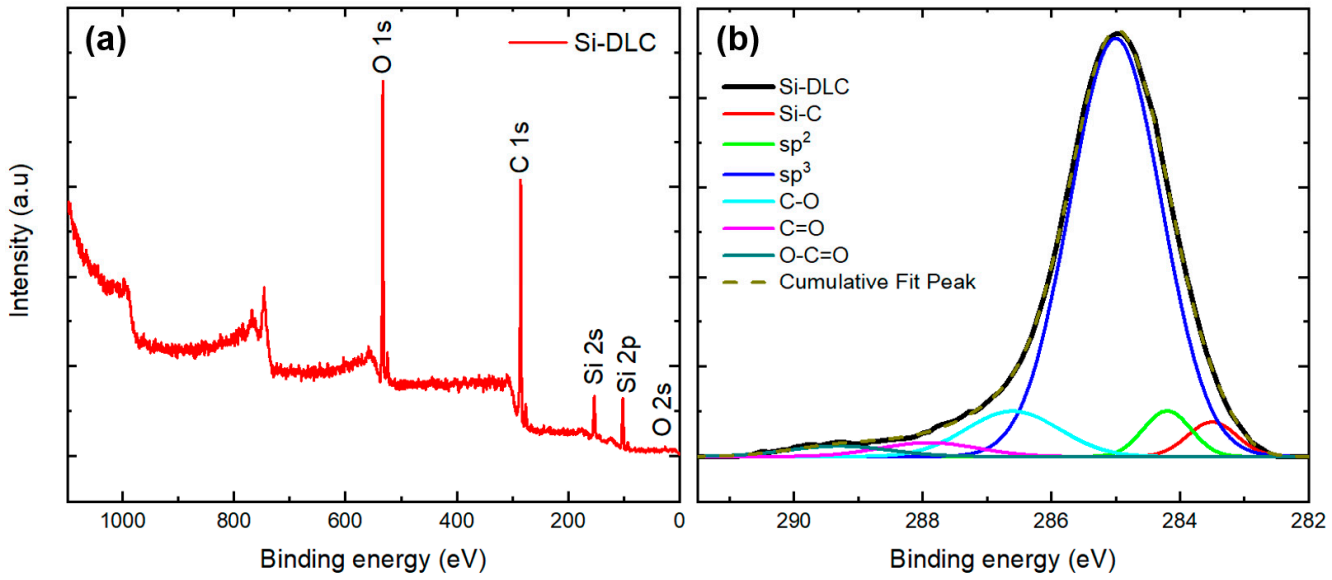

Figure 5. (a) XPS spectrum of the Si-DLC coating on a silicon substrate. (b) Deconvolution of the high-resolution $C$ 1s band of the Si-DLC coating.

A sample of the Si-DLC coating on the silicon substrate was prepared by focused ion beam (FIB) processing; EDS data was collected from the FIB-processed sample (Figure 6a). The elements were mapped in different colors; $\mathrm{Si}$ (in ochre), oxygen (in red), carbon (in green), and $\mathrm{Pt}$ (in yellow). The presence of Si was observed in the Si-DLC coating. The selective area diffraction (SAD) pattern from the Si-containing DLC coating is shown in Figure $6 \mathrm{~b}$. A small SAD aperture was used such that it only covered the Si-DLC coating; no stray signal from the $\mathrm{Si} / \mathrm{SiO}_{2}$ interface or $\mathrm{Pt}$ was noted. The diffraction shows characteristic carbon (111) and (220) rings. The diffused rings confirm the amorphous nature of the Si-DLC coating.
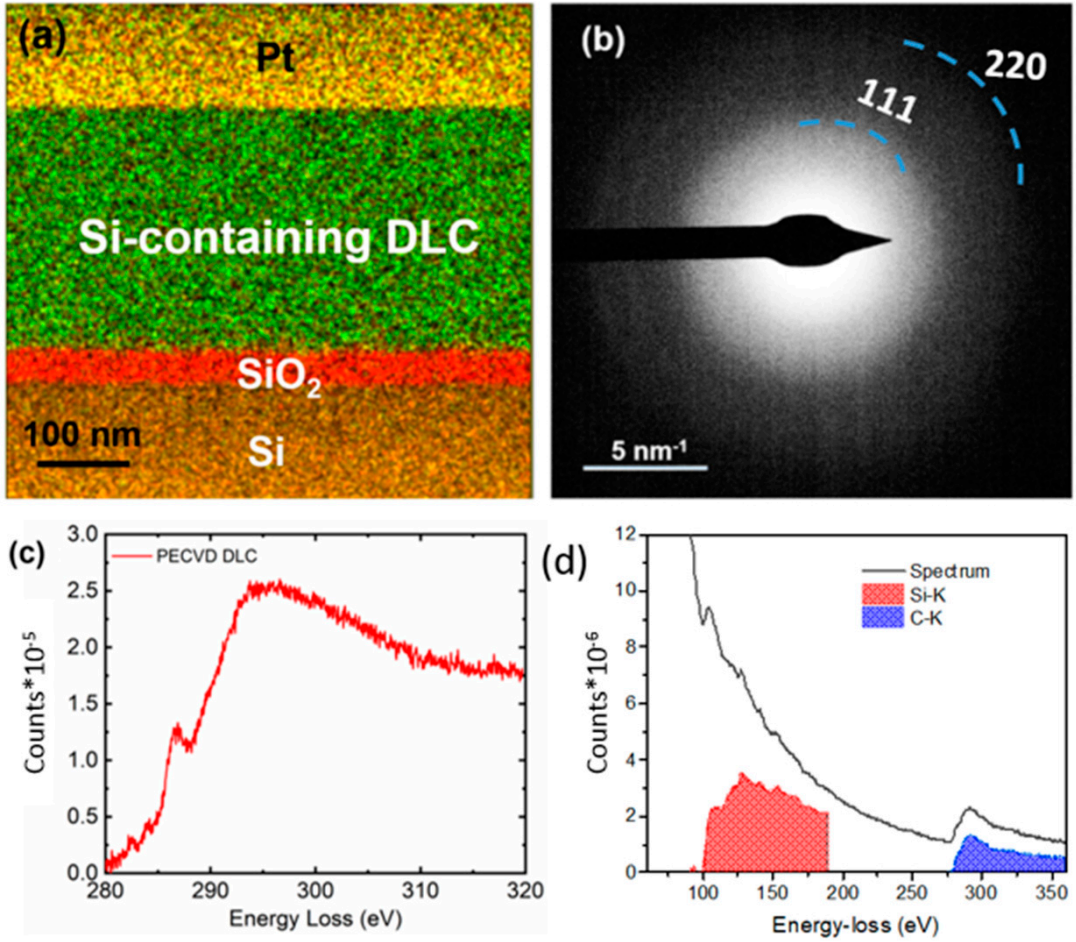

Figure 6. (a) Energy dispersive X-ray analysis of the Si-DLC coating with Si (in ochre), oxygen (in red), carbon (in green), and Pt (in yellow). (b) Selective area diffraction pattern from the Si-DLC coating, indicating the amorphous nature of the coating. (c) Electron energy loss spectrum from the Si-DLC coating. (d) Electron energy loss spectrum containing Si (red) and C (blue) edges. 
Three major edges were observed in the EELS spectrum: $\mathrm{C}=\mathrm{C}\left(\pi^{*}\right)$ at $285 \mathrm{eV}, \mathrm{C}=\mathrm{C}\left(\sigma^{*}\right)$ at $292 \mathrm{eV}$, and C-C $\left(\sigma^{*}\right)$ at $298 \mathrm{eV}$ (Figure 6c) [32]. Previous studies [33-35] have shown that the ratio of $\pi^{*} / \sigma^{*}$ determines the sp ${ }^{2}$ content of the as-deposited DLC coating. Diamond exhibits a $\sigma^{*}$ peak (but no $\pi^{*}$ peak), whereas graphite shows the presence of both peaks. Gaussian fitting was performed on the C K-edge to estimate the $\mathrm{sp}^{3}$ content of the SiDLC coating. To address the sample thickness-related plural scattering effects on the $C$ $\mathrm{K}$ edge, the estimations were done after performing thickness corrections in the EELS spectrum using a zero-loss spectrum [36]. The Si-DLC coating was determined to contain an $\mathrm{sp}^{3}$ content of $\sim 55 \%$ (Figure $6 \mathrm{c}$ ). By performing further quantification of EELS spectra containing Si K $(99 \mathrm{eV})$ and C K $(284 \mathrm{eV})$ edges as shown in Figure 6d, we estimated $\sim 18 \pm 2 \% \mathrm{Si}$ in the Si-DLC coating; this value is consistent with the results obtained by XPS.

The vapor transmission performance of the Si-DLC coated polymer material was compared with that of the uncoated polymer material. MVTR is used to describe the performance of the material to protect against moisture; a higher MVTR value is associated with a greater passage of moisture vapor through the material. Table 2 summarizes the MVTR results for the Si-DLC coated polymer material and the uncoated polymer material. The average MVTR value for the three uncoated polymer materials was measured to be $10.10\left(\mathrm{~g} / \mathrm{m}^{2} 24 \mathrm{~h}\right)$, whereas the average MVTR value for the three Si-DLC coated polymer materials was $6.31\left(\mathrm{~g} / \mathrm{m}^{2} 24 \mathrm{~h}\right)$. The decrease in the MVTR value for the Si-DLC coated polymer material of about $38 \%$ is associated with the moisture barrier performance of the Si-DLC coating.

Table 2. Moisture vapor transmission results for the uncoated polymer material and the Si-DLC coated polymer material.

\begin{tabular}{|c|c|c|c|c|c|}
\hline Sample & $\begin{array}{l}\text { Weight } 1 \\
\text { (grams) }\end{array}$ & $\begin{array}{l}\text { Weight } 2 \\
\text { (grams) }\end{array}$ & $\begin{array}{l}\text { W1-W2 } \\
\text { (grams) }\end{array}$ & $\begin{array}{c}\text { WVT } \\
\left(\mathrm{g} / \mathrm{h} \mathrm{m}^{2}\right)\end{array}$ & $\begin{array}{c}\text { MVTR } \\
\left(\mathrm{g} / \mathrm{m}^{2} 24 \mathrm{~h}\right)\end{array}$ \\
\hline Uncoated polymer (1) & 139.90 & 139.84 & 0.06 & 0.47 & 11.36 \\
\hline Uncoated polymer (2) & 138.39 & 138.33 & 0.06 & 0.47 & 11.36 \\
\hline Uncoated polymer (3) & 140.63 & 140.59 & 0.04 & 0.32 & 7.57 \\
\hline Avg. & & & 0.05 & 0.42 & 10.10 \\
\hline Si-DLC coated polymer (1) & 138.27 & 138.23 & 0.04 & 0.32 & 7.57 \\
\hline Si-DLC coated polymer (2) & 137.58 & 137.55 & 0.03 & 0.24 & 5.68 \\
\hline Si-DLC coated polymer (3) & 137.32 & 137.29 & 0.03 & 0.24 & 5.68 \\
\hline Avg. & & & 0.03 & 0.26 & 6.31 \\
\hline
\end{tabular}

To further investigate the capabilities of the Si-DLC coating related to protection against moisture, we carried out a water stability study. To perform the water stability study, the Si-DLC coatings on silicon substrates were immersed for four hours inside a deionized-filled water vessel that was kept at either room temperature or $100{ }^{\circ} \mathrm{C}$. Raman spectroscopy was conducted on the samples before and after water immersion. Figure 7 shows the Raman spectra of the Si-DLC coating before and after soaking in DI water at room temperature for four hours as well as the Raman spectra of the Si-DLC coating before and after soaking in DI water at $100{ }^{\circ} \mathrm{C}$ for four $\mathrm{h}$. As indicated in Figure $7 \mathrm{a}$, the Si-DLC coating showed no change in spectral features after four hours of immersion in room temperature DI water. No significant alteration to the Si-DLC structure as indicated by abrupt changes to the D peak and $G$ peak values was observed. The values of the $D$ peak and $G$ peak before water immersion at room temperature were $1349 \mathrm{~cm}^{-1}$ and $1495 \mathrm{~cm}^{-1}$, respectively; the values of the D peak and G peak after water immersion at room temperature were 1340 and $1504 \mathrm{~cm}^{-1}$, respectively. We also observed that the Si-DLC structure remained stable in contact with boiling water at a temperature of $100{ }^{\circ} \mathrm{C}$ for four hours (Figure $7 \mathrm{~b}$ ). Considering the resolution limitation of the Raman instrument $\left(5 \mathrm{~cm}^{-1}\right)$, the structure showed similar values for the $D$ peak and $G$ peak before and after immersion in water at $100^{\circ} \mathrm{C}$. The values of the $D$ peak and $G$ peak before water immersion at $100{ }^{\circ} \mathrm{C}$ were $1333 \mathrm{~cm}^{-1}$ and $1504 \mathrm{~cm}^{-1}$, respectively; the values of the $D$ peak and G peak after water immersion at $100{ }^{\circ} \mathrm{C}$ were 1327 and $1506 \mathrm{~cm}^{-1}$, respectively. We also performed 
a peel-off adhesion test using scotch tape on the Si-DLC coating before and after water immersion. The results indicated the high-quality adhesion of the Si-DLC coating to the silicon substrates after immersion in $100{ }^{\circ} \mathrm{C}$ water for $4 \mathrm{~h}$.
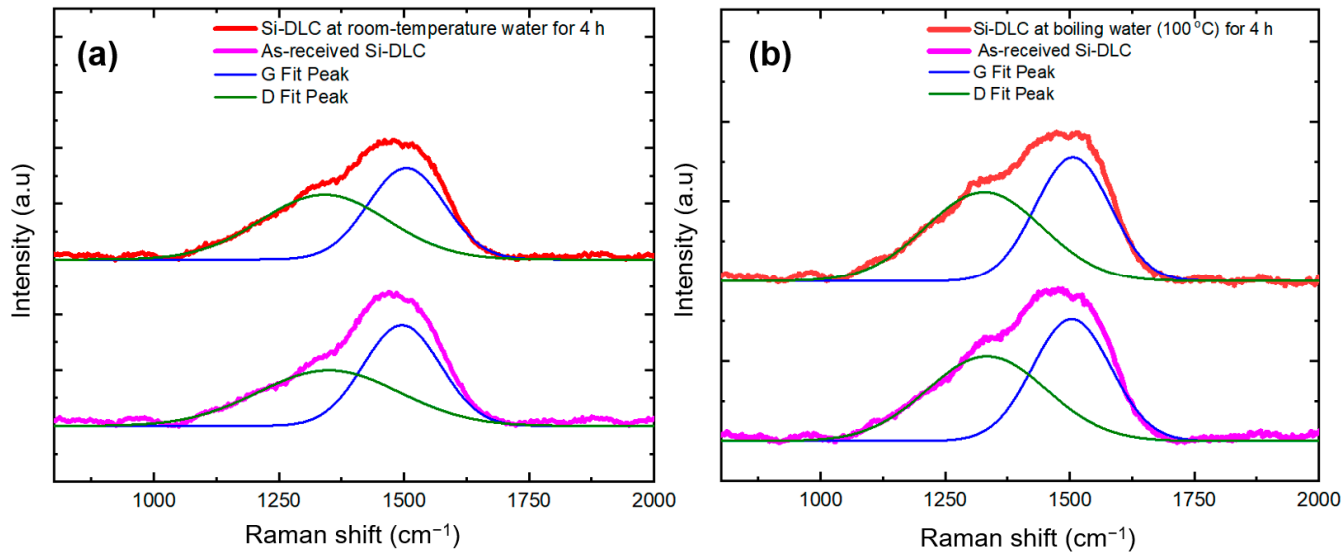

Figure 7. (a) The Raman spectra of the Si-DLC coating before and after soaking in DI water at room temperature for four hours, and (b) the Raman spectra of the Si-DLC coating before and after soaking in DI water at $100{ }^{\circ} \mathrm{C}$ for four hours.

\section{Conclusions}

We deposited Si-DLC coatings on commercial polymer materials in a cylindrical shape with large dimensions, specifically a diameter of $20.3 \mathrm{~cm}$ and a height of $17.8 \mathrm{~cm}$. We have shown that PECVD method is a suitable approach for depositing large area Si-DLC coatings. The MVTR studies indicated that the Si-DLC film can serve as a moisture barrier on polymer materials. The uniformity of the Si-DLC coating with no flaking, as indicated by AFM and FESEM studies, and the absence of contaminants, as indicated by the XPS study, indicate that this material holds promise for commercial moisture-resistant packaging applications. The water stability results show the stability of the structural stability of the Si-DLC coatings in contact with moisture up to $100{ }^{\circ} \mathrm{C}$.

Author Contributions: Conceptualization, methodology, formal analysis, investigation: P.R.R., P.J., S.A.M., R.S., J.N. and R.J.N.; writing—original draft preparation: P.R.R., P.J., S.A.M., R.S., J.N. and R.J.N. All authors have read and agreed to the published version of the manuscript.

Funding: This work was performed under a Project Award Agreement from the National Institute for Innovation in Manufacturing Biopharmaceuticals (NIIMBL) and financial assistance award 70NANB17H002 from the U.S. Department of Commerce, National Institute of Standards and Technology. The authors would also like to acknowledge the support of National Science Foundation Award \#1836767.

Institutional Review Board Statement: Not applicable.

Informed Consent Statement: Not applicable.

Data Availability Statement: The datasets generated during and/or analyzed during the current study are available from the corresponding author on reasonable request.

Acknowledgments: The authors would like to acknowledge ILC Dover LLC, particularly Andrew Koster, Steven Lloyd, Thad Fredrickson, and Steven Seichepine, for providing the polymer materials and for guiding characterization of the materials. The authors would like to acknowledge the Textile Protection and Comfort Center (TPACC) at the Wilson College of Textiles for their assistance with the MVTR studies. This work was performed in part at the NCSU Nanofabrication Facility (NNF), a member of the North Carolina Research Triangle Nanotechnology Network (RTNN), which is supported by the National Science Foundation (Grant ECCS-1542015) as part of the National Nanotechnology Coordinated Infrastructure (NNCI). This work was performed in part at the Analytical Instrumentation Facility (AIF) at North Carolina State University, which is supported by the State of 
North Carolina and the National Science Foundation (award number ECCS-2025064). R.S. acknowledges the support of faculty start-up funding at Oklahoma State University. The AIF is a member of the North Carolina Research Triangle Nanotechnology Network (RTNN), a site in the National Nanotechnology Coordinated Infrastructure (NNCI).

Conflicts of Interest: The authors declare that they have no known competing financial interests or personal relationships that could have appeared to influence the work reported in this paper.

\section{References}

1. Erdemir, A.; Donnet, C. Tribology of diamond-like carbon films: Recent progress and future prospects. J. Phys. D Appl. Phys. 2006, 39, 311. [CrossRef]

2. Aisenberg, S.; Chabot, R.W. Physics of Ion Plating and Ion Beam Deposition. J. Vac. Sci. Technol. 1973, 10, 104-107. [CrossRef]

3. Zhang, Z.; Song, R.; Li, G.; Hu, G.; Sun, Y. Improving barrier properties of PET by depositing a layer of DLC films on surface. Adv. Mater. Sci. Eng. 2013, 2013. [CrossRef]

4. Abbas, G.A.; Roy, S.S.; Papakonstantinou, P.; McLaughlin, J.A. Structural investigation and gas barrier performance of diamondlike carbon based films on polymer substrates. Carbon N. Y. 2005, 43, 303-309. [CrossRef]

5. Boutroy, N.; Pernel, Y.; Rius, J.M.; Auger, F.; Von Bardeleben, H.J.; Cantin, J.L.; Abel, F.; Zeinert, A.; Casiraghi, C.; Ferrari, A.C.; et al. Hydrogenated amorphous carbon film coating of PET bottles for gas diffusion barriers. Diam. Relat. Mater. 2006, 15, 921-927. [CrossRef]

6. Riley, P.R.; Narayan, R.J. Recent advances in carbon nanomaterials for biomedical applications: A review. Curr. Opin. Biomed. Eng. 2021, 17, 100262. [CrossRef]

7. Movahed, S.; Nguyen, A.K.; Goering, P.L.; Skoog, S.A.; Narayan, R.J. Argon and oxygen plasma treatment increases hydrophilicity and reduces adhesion of silicon-incorporated diamond-like coatings. Biointerphases 2020, 15, 041007. [CrossRef]

8. Dangnan, F.; Espejo, C.; Liskiewicz, T.; Gester, M.; Neville, A. Water barrier performance of additively manufactured polymers coated with diamond-like carbon films. Diam. Relat. Mater. 2021, 119. [CrossRef]

9. Bernsmann, F.; Laube, N.; Baldsiefen, G.; Castellucci, M. Hydrogenated amorphous carbon coatings on implants drastically reduce biofilm formation and water permeation. In Proceedings of the Journal of Physics: Conference Series; 2014; Volume 564, p. 12001. Available online: https://www.researchgate.net/publication/285971216_Hydrogenated_amorphous_carbon_coatings_ on_implants_drastically_reduce_biofilm_formation_and_water_permeation (accessed on 10 October 2021).

10. Abbas, G.A.; McLaughlin, J.A.; Harkin-Jones, E. A study of ta-C, a-C:H and Si-a:C:H thin films on polymer substrates as a gas barrier. Diam. Relat. Mater. 2004, 13, 1342-1345. [CrossRef]

11. Maeda, M.; Watanabe, T. Evaluation of photocatalytic properties of titanium oxide films prepared by plasma-enhanced chemical vapor deposition. Thin Solid Films 2005, 489, 320-324. [CrossRef]

12. Sun, Z.; Lin, C.H.; Lee, Y.L.; Shi, J.R.; Tay, B.K.; Shi, X. Properties and structures of diamond-like carbon film deposited using He, $\mathrm{Ne}, \mathrm{Ar} /$ methane mixture by plasma enhanced chemical vapor deposition. J. Appl. Phys. 2000, 87, 8122-8131. [CrossRef]

13. Varanasi, V.G.; Velten, M.F.; Odatsu, T.; Ilyas, A.; Iqbal, S.M.; Aswath, P.B. Surface Modifications and Surface Characterization of Biomaterials Used in Bone Healing. In Materials and Devices for Bone Disorders; Elsevier: Amsterdam, The Netherlands, 2017; pp. 405-452, ISBN 9780128028032.

14. Franz, G. Plasma enhanced chemical vapor deposition of organic polymers. Processes 2021, 9, 980. [CrossRef]

15. Guo, C.T. Diamond-like carbon films deposited on polycarbonates by plasma-enhanced chemical vapor deposition. Thin Solid Films 2008, 516, 4053-4058. [CrossRef]

16. Hess, D.W. Plasma-Surface Interactions in Plasma-Enhanced Chemical Vapor Deposition; Annual Reviews Inc.: Palo Alto, CA, USA, 1986; Volume 16, ISBN 0824317165.

17. Vasudev, M.C.; Anderson, K.D.; Bunning, T.J.; Tsukruk, V.V.; Naik, R.R. Exploration of plasma-enhanced chemical vapor deposition as a method for thin-film fabrication with biological applications. ACS Publ. 2013, 5, 3983-3994. [CrossRef] [PubMed]

18. Bute, A.; Jena, S.; Kedia, S.; Udupa, D.V.; Singh, K.; Bhattacharya, D.; Modi, M.H.; Chand, N.; Sinha, S. Boron carbide thin films deposited by RF-PECVD and PLD technique: A comparative study based on structure, optical properties, and residual stress. Mater. Chem. Phys. 2021, 258. [CrossRef]

19. Ullah, Z.; Riaz, S.; Li, Q.; Atiq, S.; Saleem, M.; Azhar, M.; Naseem, S.; Liu, L. A comparative study of graphene growth by APCVD, LPCVD and PECVD. Mater. Res. Express 2018, 5. [CrossRef]

20. Bonetti, L.F.; Capote, G.; Santos, L.V.; Corat, E.J.; Trava-Airoldi, V.J. Adhesion studies of diamond-like carbon films deposited on Ti6Al4V substrate with a silicon interlayer. Thin Solid Films 2006, 515, 375-379. [CrossRef]

21. Delfani-Abbariki, S.; Abdollah-zadeh, A.; Hadavi, S.M.M.; Abedi, M.; Derakhshandeh, S.M.R. Enhancing the adhesion of diamond-like carbon films to steel substrates using silicon-containing interlayers. Surf. Coat. Technol. 2018, 350, 74-83. [CrossRef]

22. Randeniya, L.K.; Bendavid, A.; Martin, P.J.; Amin, M.S.; Preston, E.W.; Magdon Ismail, F.S.; Coe, S. Incorporation of Si and $\mathrm{SiOx}$ into diamond-like carbon films: Impact on surface properties and osteoblast adhesion. Acta Biomater. 2009, 5, $1791-1797$. [CrossRef] [PubMed]

23. Ferrari, A.; Robertson, J. Interpretation of Raman spectra of disordered and amorphous carbon. Phys. Rev. B-Condens. Matter Mater. Phys. 2000, 61, 14095-14107. [CrossRef] 
24. Ferrari, A.C.; Robertson, J. Origin of the $1150-\mathrm{cm}-1$ Raman mode in nanocrystalline diamond. Phys. Rev. B-Condens. Matter Mater. Phys. 2001, 63. [CrossRef]

25. Ferrari, A.C.; Robertson, J. Raman spectroscopy of amorphous, nanostructured, diamond-like carbon, and nanodiamond. Philos. Trans. R. Soc. A Math. Phys. Eng. Sci. 2004, 362, 2477-2512. [CrossRef] [PubMed]

26. Papakonstantinou, P.; Zhao, J.F.; Lemoine, P.; McAdams, E.T.; McLaughlin, J.A. The effects of Si incorporation on the electrochemical and nanomechanical properties of DLC thin films. Diam. Relat. Mater. 2002, 11, 1074-1080. [CrossRef]

27. Wang, J.; Liu, G.; Xu, J.; Deng, X.; Wang, L. Nanomechanical and electrochemical properties of diamond-like carbon (DLC) films deposited by plasma enhanced chemical vapor deposition (PECVD) technique. Plasma Sci. Technol. 2010, 12, 461-465. [CrossRef]

28. Önneby, C.; Pantano, C.G. Silicon oxycarbide formation on $\mathrm{SiC}$ surfaces and at the SiC/SiO2 interface. J. Vac. Sci. Technol. A Vac. Surf. Film. 1997, 15, 1597-1602. [CrossRef]

29. B, S.; S, T.R.; Martin, P.J.; Vaithilingam, V.; Bean, P.A.; Evans, M.D.M.; Bendavid, A. Biomineralization of osteoblasts on DLC coated surfaces for bone implants. Biointerphases 2018, 13, 041002. [CrossRef]

30. Bociaga, D.; Sobczyk-Guzenda, A.; Komorowski, P.; Balcerzak, J.; Jastrzebski, K.; Przybyszewska, K.; Kaczmarek, A. Surface characteristics and biological evaluation of Si-DLC coatings fabricated using magnetron sputtering method on Ti6Al7 Nb substrate. Nanomaterials 2019, 9, 812. [CrossRef] [PubMed]

31. Santini, C.A.; Sebastian, A.; Marchiori, C.; Jonnalagadda, V.P.; Dellmann, L.; Koelmans, W.W.; Rossell, M.D.; Rossel, C.P.; Eleftheriou, E. Oxygenated amorphous carbon for resistive memory applications. Nat. Commun. 2015, 6. [CrossRef]

32. Sachan, R.; Gupta, S.; Narayan, J. Nonequilibrium Structural Evolution of Q-Carbon and Interfaces. ACS Appl. Mater. Interfaces 2020, 12, 1330-1338. [CrossRef]

33. Bruley, J.; Williams, D.B.; Cuomo, J.J.; Pappas, D.P. Quantitative near-edge structure analysis of diamond-like carbon in the electron microscope using a two-window method. J. Microsc. 1995, 180, 22-32. [CrossRef]

34. Bernier, N.; Bocquet, F.; Allouche, A.; Saikaly, W.; Brosset, C.; Thibault, J.; Charaï, A. A methodology to optimize the quantification of sp2 carbon fraction from K edge EELS spectra. J. Electron Spectros. Relat. Phenomena 2008, 164, 34-43. [CrossRef]

35. Galvan, D.; Pei, Y.T.; De Hosson, J.T.M.; Cavaleiro, A. Determination of the sp3 C content of a-C films through EELS analysis in the TEM. Surf. Coat. Technol. 2005, 200, 739-743. [CrossRef]

36. Sachan, R.; Hachtel, J.A.; Bhaumik, A.; Moatti, A.; Prater, J.; Idrobo, J.C.; Narayan, J. Emergence of shallow energy levels in B-doped Q-carbon: A high-temperature superconductor. Acta Mater. 2019, 174, 153-159. [CrossRef] 